\title{
ESTIMATION HOURLY GLOBAL RADIATION UNDER CLEAR SKY CONDITIONSIN SOUTHEASTERN ANATOLIA REGION OF TURKEY
}

DOI: http://dx.doi.org/10.18509/GBP.2015.11

UDC: 551.521.1.06:620.92(560)

\author{
Zeynep KÜÇÜKDERE \\ Prof. Dr. Sema TOPCU \\ Department of Atmospheric Science, İstanbul Technical University, Maslak, İstanbul - Turkey
}

\begin{abstract}
Growing concern over the world's increasing energy needs and rapid decreasing reserves of oil, natural gas, and fuel have put in action to develop alternative energy sources. Modern world have increasing population day by day lead to have new energy sources for reply to people's needs. Solar energy is widely accepted as a crucial energy source for around the world with respect to the environmental concerns associated with fossil fuels as well as their limited reserves.

Turkey has a better chance than other countries in terms of solar energy potential because of its geographical situation in the northern hemisphere with latitudes of 36-42 N and longitude of 26-45 E. The annual average sunshine duration of Turkey is 2640 hours. Yearly total radiation intensity per square meter is $1311 \mathrm{kWh}$. Southeastern Anatolia region has maximum radiation potential and maximum sunlight duration all over the year. The average total solar radiation in annual of Southeastern Anatolia is $1460 \mathrm{kWh} / \mathrm{m}^{2}$, maximum sunlight duration is 407 hours in month June and total sunlight duration is 2993 hours.

Knowledge of hourly global radiation under the clear atmosphere is important for many solar radiation model. In this study, the models of Haurwitz, Berger and Kasten \& Czeplak are tested for hourly global radiation estimation under clear sky conditions for Bozova and Ceylanpınar in Turkey. Solar zenith angle is the focus point for the models. RMSE is used for comparing model results with the measurements. Haurwitz the relative RMSE value for Bozova is 0.00316 and 0.00691 for Ceylanpınar. As a results, it is find that Haurwitz Model performed better than others.
\end{abstract}

Keywords: Solar radiation prediction, clear sky radiaton, zenith angle

\section{INTRODUCTION}

The sunlight arrived the surface of the earth is depending on the location of a place. Location means that the places's latitude and longitude. Turkey has a better chance than other countries in terms of solar energy potential due to its geographical situation in the northern hemisphere with latitudes of 36-42 $\mathrm{N}$ and longitude of 26-45 E. The annual average sunshine duration of Turkey is 2640 hours per square meter (Daily total sunshine duration is 7.2 hour). Yearly total radiation intensity per square meter is $1311 \mathrm{kWh}$ in Turkey. According to GEPA (Solar Energy Potential Atlas for Turkey) concerning of sunlight duration and solar radiation potential, the most lucky region is Southeasthern Anatolia in Turkey (Fig.1). This region has maximum radiation potential and max sunlight duration all over the year. The total solar radiation of monthly reaches it is maximum value in June, and the minumum one occurs in December. The annual total solar radiation of Southeastern Anatolia is $1460 \mathrm{kWh} / \mathrm{m}^{2}$, maximum sunshine duration is 
407 hours in June and yearly total sunlight duration is 2993 hours while the country has an average $1311 \mathrm{kWh} / \mathrm{m} 2$ year and 2640 hour sunshine duration [EIEI, 2013].
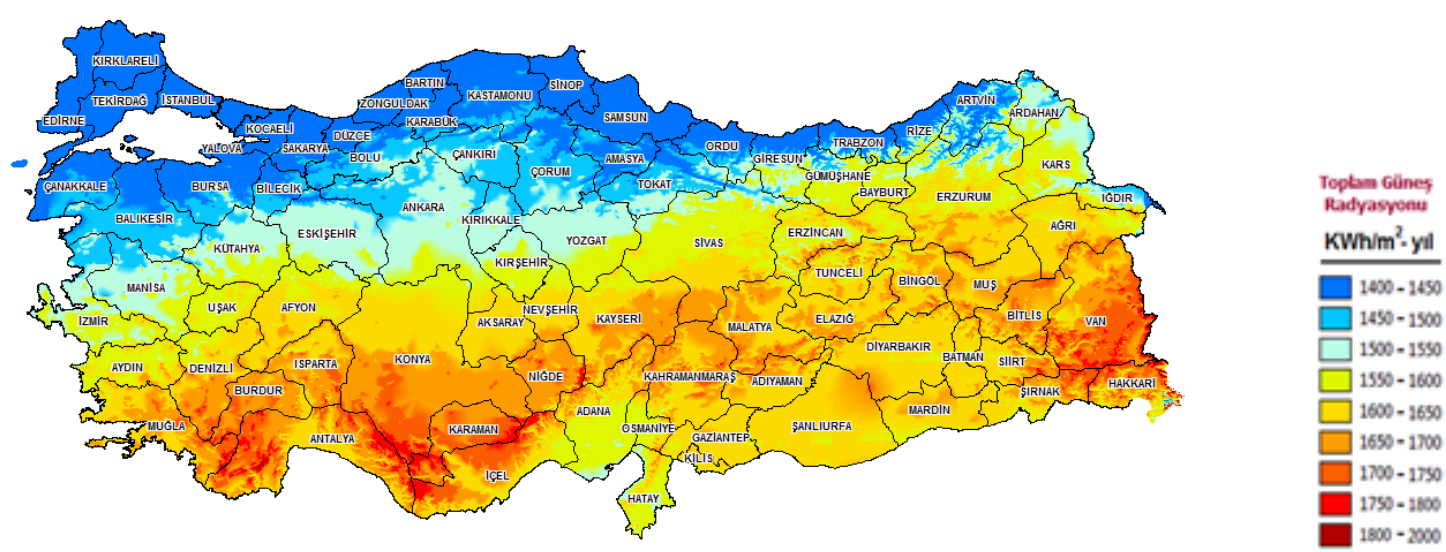

Figure 1: Solar energy potential atlas, GEPA [1]

In literature various global solar radiation models have been developed and tested for many different climatic areas was estimate the average global solar radiation based on sunshine model in Turkey [2] [3] [4]. In this paper, three basic models are choosen for estimating incoming hourly solar radiation in clear atmosphere and tested for Bozova and Ceylanpinar.The concern parameter selected models is solar zenith angle values.

\section{DATA AND METHOD}

Bozova and Ceylanpınar is situated in the Southeastern Anatolia Reagion. The region has a semi-arid continental climate with Mediterranean influence. Locations of Bozova and Ceylanpınar are shown in Tablo 1 . In the study hourly global radiation and daily sunshine duration data for 2011 are used. The days have the daily sunlight duration ratio higher than 0.7, that day is accepted as clear day. Clear days are shown seasonaly in Table 2. In this study, Haurwitz Model, Berger Model, Kasten and Czeplak Model are considered to estimate clear sky global radiation. The models which are used in this paper are shown in Table 3;

Table 1: Location information of Bozova and Ceylanpınar

\begin{tabular}{|c|c|c|c|}
\hline Station name & Latitude & Longtitude & Height \\
\hline Bozova & $37,3651 \mathrm{~N}$ & $38,5134 \mathrm{E}$ & $519 \mathrm{~m}$ \\
\hline Ceylanpinar & $36,84 \mathrm{~N}$ & $40.03 \mathrm{E}$ & $360 \mathrm{~m}$ \\
\hline
\end{tabular}

Table2: Models used in this paper

\begin{tabular}{|c|c|}
\hline Equation & Reference \\
\hline $\mathrm{G}_{\mathrm{c}}=1098 * \cos \left(\boldsymbol{\Theta}_{\mathrm{z}}\right) * \mathrm{e}^{-0.057 / \cos (\theta \mathrm{z})}$ & Haurwitz (1945-1946) [3] \\
\hline $\mathrm{G}_{\mathrm{c}}=1350 * 0.70 * \cos \left(\boldsymbol{\Theta}_{\mathrm{z}}\right)$ & Berger (1979) [2] \\
\hline $\mathrm{G}_{\mathrm{c}}=910 * \cos \left(\boldsymbol{\Theta}_{\mathrm{z}}\right)-30$ & Kasten ve Czeplak (1980) [4] \\
\hline
\end{tabular}

$\Theta_{\mathrm{z}}$, is hourly solar zenith angle and is calculated following equation.

$$
\cos \left(\Theta_{\mathbf{z}}\right)=\sin (\delta) * \sin (\varphi)+\cos (\delta) * \cos (\delta) * \cos (\mathrm{w})
$$

where $\delta$ is declination angle; $\varphi$ is latitude angle and $w$ is hour angle. 
Table 3: Choosen clear days

\begin{tabular}{|c|c|c|}
\hline Season & Bozova & Ceylanpınar \\
\hline winter & February 7-12 & February 6-8 \\
\hline spring & March 25-29 & May 22-24 \\
\hline summer & July 3-11 & July 1-11 \\
\hline fall & Semptember 6-13 & Semptember 13-15 \\
\hline
\end{tabular}

\section{RESULTS}

In this paper for the choosen clear days, hourly global solar radiation radiation is calculated for all three models seperateltly. Hourly distributions of model outputs and observed data for Bozova are showned in Figure 2-Figure 5 for choosen days included in winter, spring, fall and summer.Hourly distributions of model outputs and observed data for Ceylanpinar are showned in Figure 2-Figure 5 for choosen days included in winter, spring, fall and summer. In general, hourly distributions of calculated global radiation and observed data are in sync. Differences between model and observed data are seen at the near of the solar noon.

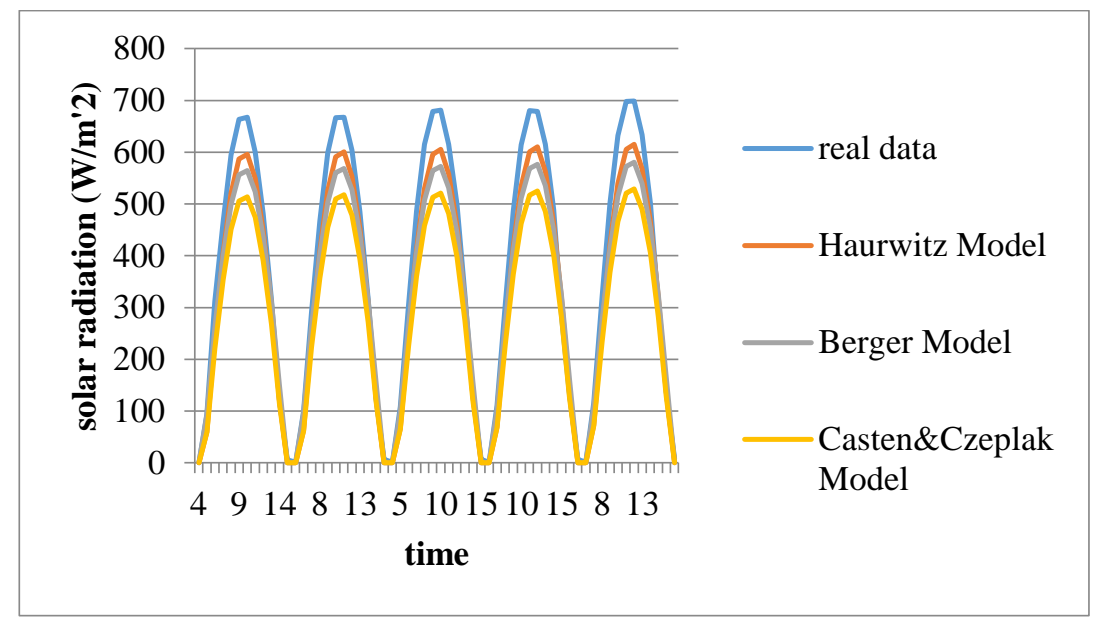

Figure 2: Winter season graphic " real data to models outputs” for Bozova 2011

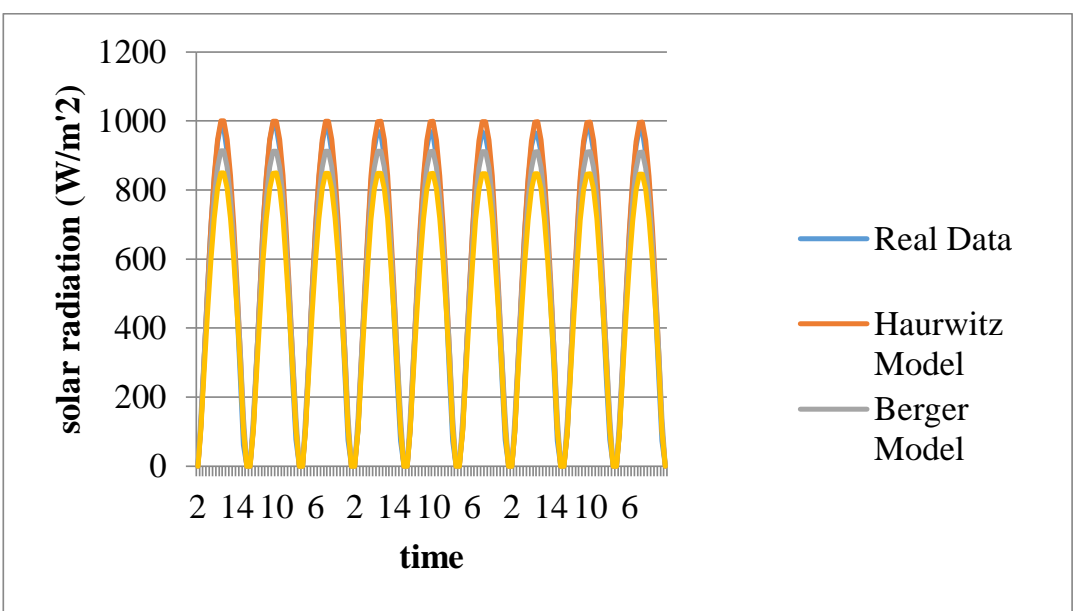

Figure 3: Summer season graphic " real data to models outputs" for Bozova 2011 


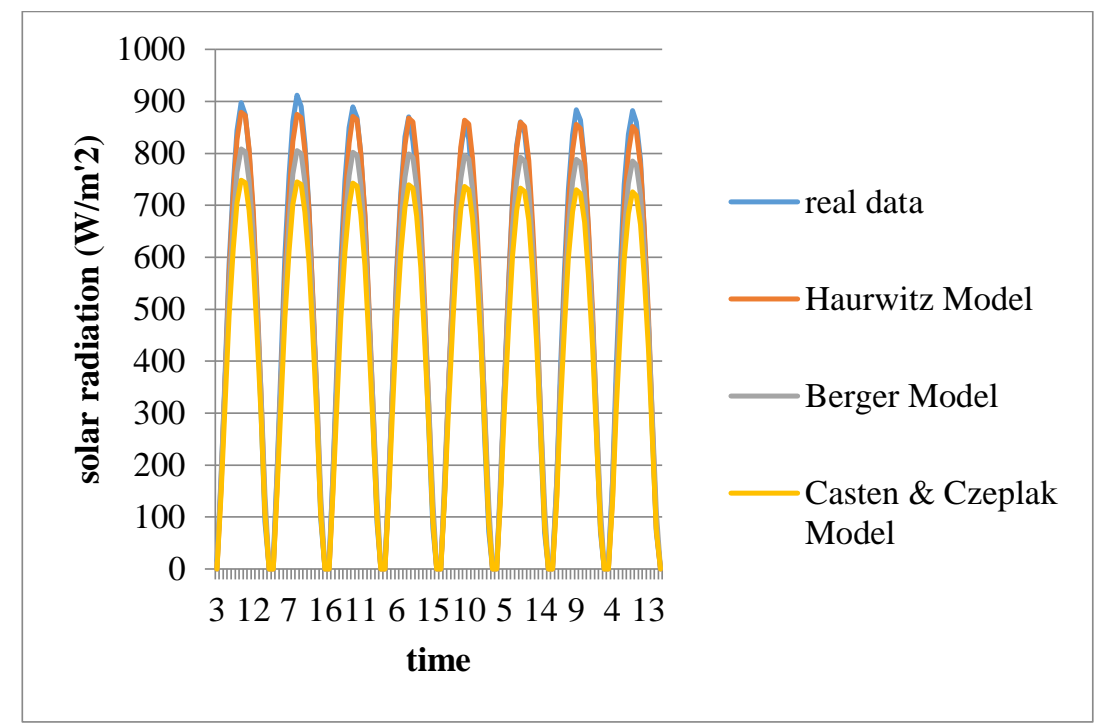

Figure 4: Fall season graphic “ real data to models outputs” for Bozova 2011

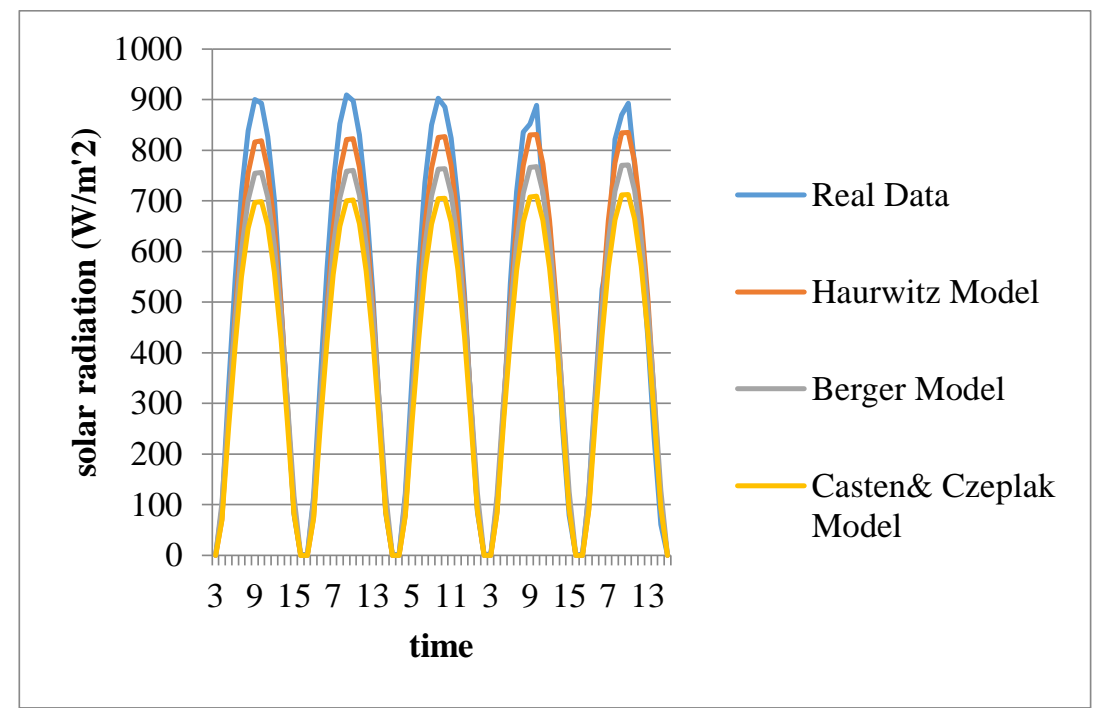

Figure 5: Spring season graphic " real data to models outputs" for Bozova 2011

For Winter and Spring period of choosen days, model outputs are located belowed observed data. Haurwitz Model is the best fitted with the observed data.

For Summer, comparing is made for 9 choosen days. Haurwitz Model shows perfect accordance with the observed data. In Fall, for the choosen 8 days, Haurwitz Model is successful. 


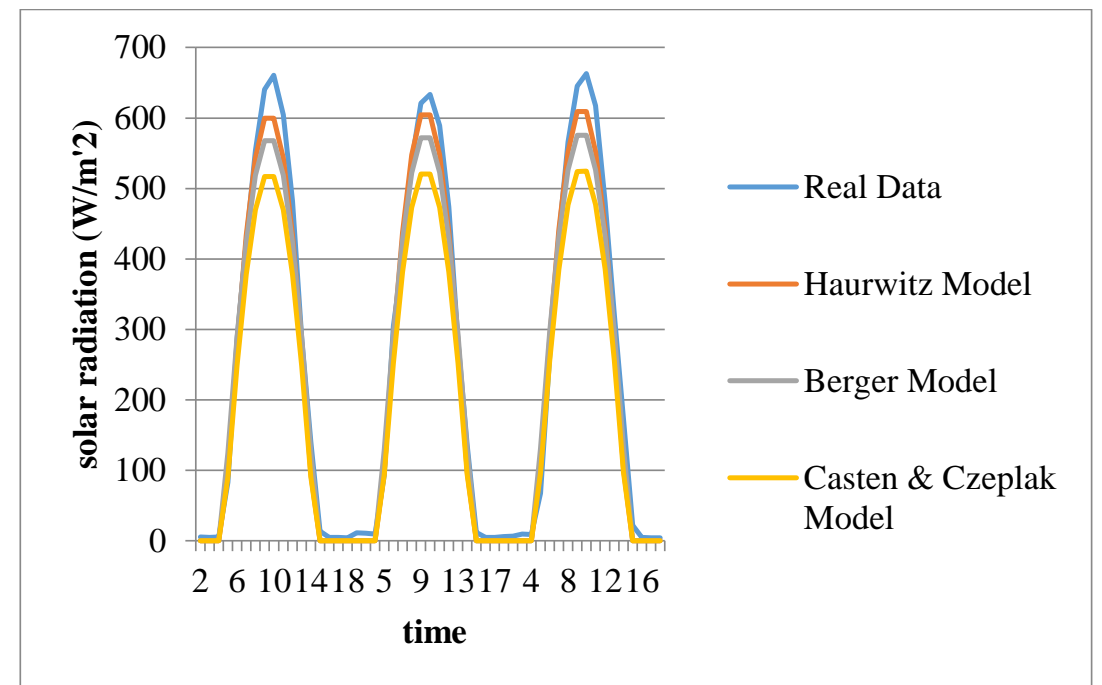

Figure 6: Winter season graphic "real data to models outputs" for Ceylanpınar 2011

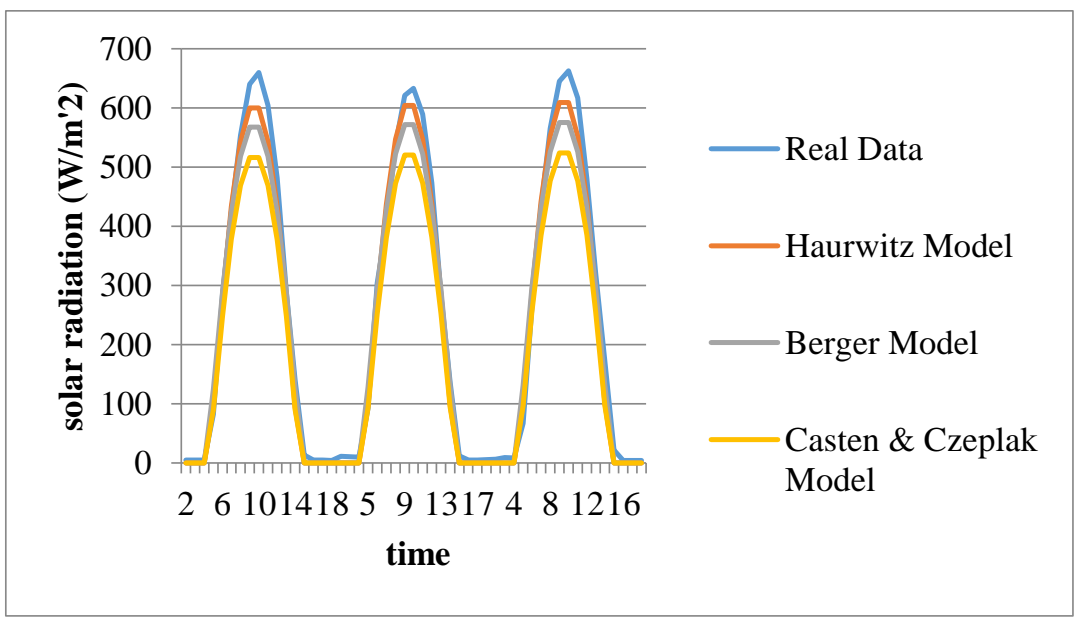

Figure 7: Summer season graphic "real data to models outputs" for Ceylanpınar 2011

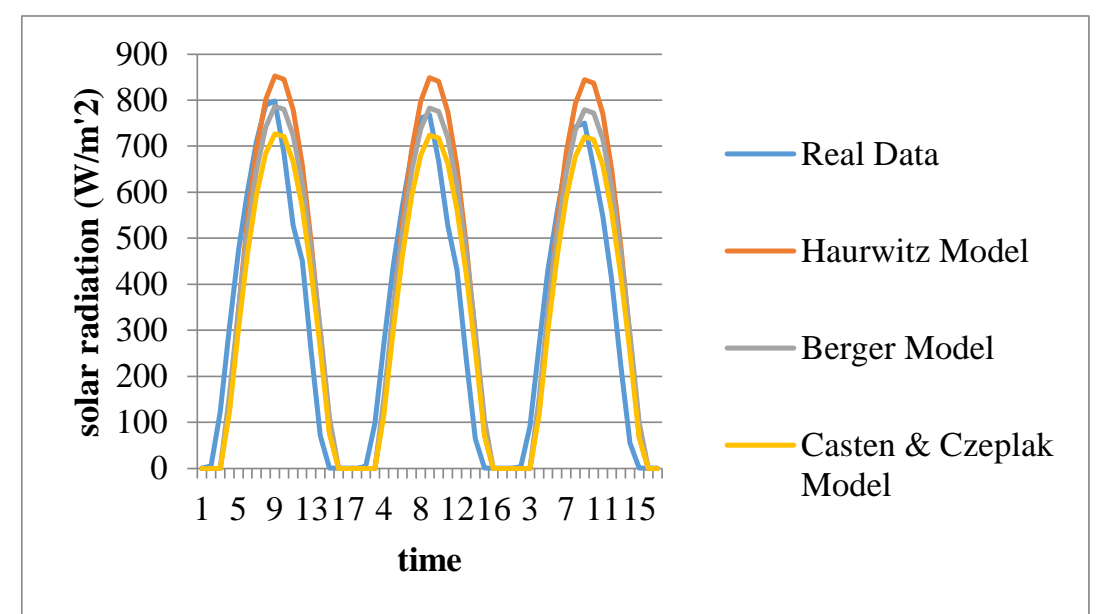

Figure 8: Fall season graphic "real data to models outputs" for ceylanpinar 2011 


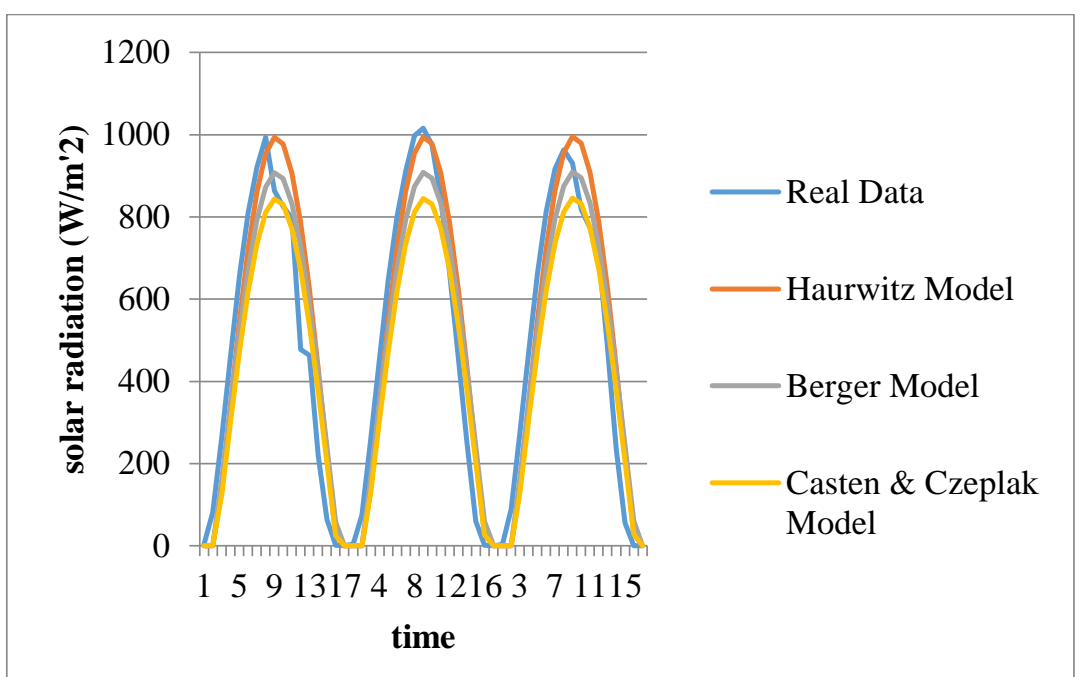

Figure 9: Spring season graphic " real data to models outputs" for ceylanpınar 2011

For Winter, Summer and Fall period of choosen days, model outputs are estimated under the observed data. But Haurwitz Model shows the best fitting.

Second day (May 23) of Spring period, there is a good accommodation with Haurwitz Model and observed global solar radiation data.

In conclusion Haurwitz Model have a better performance from the other models for Bozova and Ceylanpınar. When considering the RMSE error calculations Haurwitz Model is more successful for Bozova.

In this study the performance of the models is evaluated in terms of the root mean squarw error (RMSE) and relative RMSE (rRMSE). RMSE and rRMSE for Ceylanpinar and Bozova are shown in Table 3 and Table 4.

Table 4: RMSE and rRMSE values for Bozova

\begin{tabular}{|c|c|c|c|c|}
\hline & Error type & Haurwitz & Berger & Kasten\&Czeplak \\
\hline February & RMSE $\left(\mathbf{W} / \mathbf{m}^{2}\right)$ & 58,28 & 74,20 & 114,37 \\
\hline & $\mathbf{R M S E \%}$ & 1,85 & 0,03 & 0,08 \\
\hline March & $\mathbf{R M S E}\left(\mathbf{W} / \mathbf{m}^{\mathbf{2}}\right)$ & 54,46 & 84,72 & 124,01 \\
\hline & $\mathbf{R M S E \%}$ & 1,00 & 0,02 & 0,06 \\
\hline July & $\mathbf{R M S E}\left(\mathbf{W} / \mathbf{m}^{\mathbf{2}}\right)$ & 38,19 & 47,45 & 80,88 \\
\hline & $\mathbf{R M S E \%}$ & 0,38 & 0,00 & 0,02 \\
\hline September & $\mathbf{R M S E}\left(\mathbf{W} / \mathbf{m}^{\mathbf{2}}\right)$ & 31,01 & 54,55 & 94,69 \\
\hline & $\mathbf{R M S E \%}$ & 0,31 & 0,01 & 0,03 \\
\hline
\end{tabular}

Table 5 : RMSE and rRMSE values for Ceylanpınar

\begin{tabular}{|c|c|c|c|c|}
\hline & & Haurwitz & Berger & Kasten\&Czeplak \\
\hline \multirow[t]{2}{*}{ February } & $\operatorname{RMSE}\left(\mathrm{W} / \mathrm{m}^{2}\right)$ & 34,43 & 50,37 & 85,57 \\
\hline & RMSE \% & 0,69 & 1,51 & 4,90 \\
\hline \multirow[t]{2}{*}{ May } & $\operatorname{RMSE}\left(\mathrm{W} / \mathrm{m}^{2}\right)$ & 125,75 & 119,27 & 139,91 \\
\hline & RMSE \% & 3,42 & 3,29 & 4,94 \\
\hline \multirow[t]{2}{*}{ July } & $\operatorname{RMSE}\left(\mathrm{W} / \mathrm{m}^{2}\right)$ & 289,94 & 268,13 & 279,44 \\
\hline & RMSE \% & 16,37 & 15,02 & 17,78 \\
\hline \multirow[t]{2}{*}{ September } & $\operatorname{RMSE}\left(\mathbf{W} / \mathbf{m}^{2}\right)$ & 147,35 & 118,67 & 116,88 \\
\hline & RMSE \% & 6,246 & 4,30 & 4,57 \\
\hline
\end{tabular}




\section{REFERENCES}

[1] EIEI, (2013) General directorate of electrical power resources survey and development administration. http://www.eie.gov.tr/eie-web/english/solar/solarTurkey [2] Badescu, V. (1997). Verification of some very simple clear and cloudy sky model to evaluate global solar irradience. Candida Oancea Institute of Solar Energy, Faculty of Mechanical Engineering, Polytechnic University of Bucharest, Spl Independentei 313, Bucharest 79590,Romania

[3] Ianetz, Amiran., Lyubansky, V., Setter, I., Kriheli, B., Evseev, G., Kudish, I. (2006). Inter-comparison of different models for estimating clear sky solar global radiation for the Negev region of Israel. Research and Development Division, Israel Meteorological Service, P.O Box 25, Bet Dagan 50205, Israel Ashqelon Academic College, P.O Box 9071, Asheqelon 78211srael

[4] Togrul, T., Togrul, H., Evin, D. (1999). Estimation of global solar radiation under clear sky radiation in Turkey. Firat University, Faculty of Engineering, Chemical Engineering Department, 23279, Elazı̆̆, Turkey. Firat University, Faculty of Engineering, Mechanical Engineering Department, 23279, Elazığ, Turkey.

[5] Berger X. (1979). Etude du Climat en Region Nicoise en vue d'Applications a I'Habitat Solaire. Paris: CNRS; 1979

[6] Czeplak G., Kasten F. (1980). Solar and Terrestrial Radiation dependent on the amount and type of clouds. Sol Energy 1980;24:177-89

[7] Haurwitz B. (1945). Insolation in relation to cloudiness and cloudy density. $J$. Meteorol 1945;2:154-66 
International Scientific Conference GEOBALCANICA 2015 